\title{
Clinical and diagnostic value of the combination of lymphocyte count and creatine kinase in the detection of coronavirus 2019
}

\author{
YANQING DU $^{1 *}$, XIANG WANG $^{2 *}$, ZHONGHUA QIN $^{1}$ and LIXIA ZHANG ${ }^{1}$ \\ Departments of ${ }^{1}$ Clinical Laboratory and ${ }^{2}$ Prevention, Tianjin Haihe Hospital, Jinnan, Tianjin 300350, P.R. China
}

Received September 9, 2020; Accepted February 5, 2021

DOI: $10.3892 / \mathrm{etm} .2021 .10073$

\begin{abstract}
The present study aimed to investigate the diagnostic efficiency of the absolute number of lymphocytes (LYM) and creatine kinase (CK) levels in the diagnosis of coronavirus disease 2019 (COVID-19). For this, the clinical data from 84 patients with COVID-19 admitted to Tianjin Haihe Hospital (Tianjin, China) between January and February 2020 were collected. The patients were divided into the following groups: The common COVID-19 group ( $\mathrm{n}=61)$ and severe COVID-19 group $(n=23)$. In addition, 30 healthy subjects were included as a control group. The results demonstrated that the percentage of neutrophils (NEU\%) was significantly increased, while the absolute number of white blood cells, LYM and the percentage of lymphocytes (LYM\%) were significantly decreased in patients with COVID-19. Furthermore, in the severe group, the absolute number of red blood cells in female patients, the NEU\%, the neutrophil-to-lymphocyte ratio (NLR) and the serum levels of interleukin- 6 and C-reactive protein (CRP) were markedly elevated, while those of LYM and LYM\% were significantly decreased (all $\mathrm{P}<0.05$ ). In addition, in the receiver operating characteristics curve analysis for the combination of LYM + CK, the area under the curve values were 0.96 and 1.00 , with a sensitivity of 95.08 and $100 \%$, specificity of 86.67 and $100 \%$ and cut-off values of 0.42 and 0.50 for the common and severe COVID-19 group, respectively. The results indicated that the diagnostic efficiency of LYM + CK was higher than that of each single factor. Finally, a moderate correlation of lactate dehydrogenase with CRP and NLR ( $\mathrm{r}=0.492$ and 0.433 , respectively; both $\mathrm{P}<0.05$ ) was obtained. Overall, the results of the present study indicated that the values of LYM and CK were associated with the progression of COVID-19, suggesting that the combination of both factors may be of clinical diagnostic value for COVID-19.
\end{abstract}

Correspondence to: Dr Lixia Zhang, Department of Clinical Laboratory, Tianjin Haihe Hospital, 890 Jingu Road, Jinnan, Tianjin 300350, P.R. China

E-mail: zhangli5839@163.com

*Contributed equally

Key words: coronavirus disease 2019, lymphocyte count, creatine kinase, C-reactive protein, diagnostic efficiency

\section{Introduction}

Coronavirus disease 2019 (COVID-19) has spread worldwide and has seriously threatened human health and the global social and economic order. Although China has taken effective measures to control the epidemic, the increasing number of imported cases and asymptomatic carriers make prevention and control measures, such as some air travel restrictions, even more necessary $(1,2)$. In general, the clinical manifestations of COVID-19 include fever (3), fatigue (4), cough (5), sore throat (6), headache (7) and joint pain (8). In severe cases, breathing difficulties, chest pain and even acute heart injury may occur. The absolute number of red blood cells (RBC), white blood cells (WBC), lymphocytes (LYM) and neutrophils (NEU), as well as the percentage of NEU (NEU\%) and LYM (LYM\%) and the serum levels of interleukin-6 (IL-6) and C-reactive protein (CRP) are considered as important indicators of inflammation, reflecting the inflammatory state of patients with COVID-19. In addition, lactate dehydrogenase (LDH), creatine kinase (CK) and CK isoenzyme (CK-Mb) are crucial biochemical markers of heart damage. Therefore, increased levels of myocardial enzymes indicate that the patient's condition is severe. Patients with COVID-19 may also exhibit impaired liver function, which may be indicated by the levels of alkaline phosphatase (ALP). Therefore, at Tianjin Haihe Hospital (Tianjin, China), the aforementioned indicators are mainly detected.

In the present study, blood parameters, IL-6 levels, neutrophil-to-lymphocyte ratio (NLR), CRP and kinase levels, liver function and other routine biochemical test results from patients with COVID-19 were recorded in order to evaluate their diagnostic efficacy and association with COVID-19. Thereby, the present study aimed to provide a reference for the early clinical diagnosis and treatment of patients with COVID-19.

\section{Materials and methods}

Patients. The present study retrospectively analyzed 84 cases of confirmed COVID-19, with 30 healthy individuals included as the control group. Patients with COVID-19 tested positive for severe acute respiratory syndrome coronavirus 2 (SARS-CoV-2) nucleic acid at Tianjin Haihe Hospital (Tianjin, China) between January and February 2020, according to real-time fluorescent quantitative PCR detection of throat 
swab specimens. The diagnostic criteria and clinical classification were based on the 'Diagnosis and Treatment Plan for COVID-19' (fifth trial version) (9). Newly diagnosed and untreated patients were included in the patient group, while cured patients with no recurrence of symptoms at the time-point of discharge were included in the cured group. The baseline characteristics of patients and healthy individuals are listed in Table I. In brief, 37 male and 47 female patients, aged 21-91 years (median age, 51 years) were enrolled in the patient group. According to the clinical classification of COVID-19, 61 cases were of the common type and 23 were severe. In the voluntary healthy group, 14 males and 16 females aged 22-80 years (median age, 51 years) were included. There were no statistically significant differences in the clinical characteristics between the healthy and patient groups. This study was approved by the Ethics Committee of the Tianjin Haihe Hospital (Tianjin, China) and patients provided their written informed consent for participating in the current study.

Reagents and instruments. The automatic biochemical immunoanalyzer VITROS 5600 with clinical chemistry rapid quantitative multilayer film technology and the CK (cat. no. 8749396), CK-Mb (cat. no. 8058232), LDH (cat. no. 8384489) and ALP detection kits (cat. no. 65240528) were purchased from Ortho-Clinical Diagnostics, Inc. The Pylon3D cycle enhanced fluorescence immunoassay analyzer with cyclic enhanced fluorescence immunoassay technology and the CRP (cat. no. 200057) and IL-6 (cat. no. 200107) detection kits were obtained from Xingtong Medical Technology Co., Ltd. The XT-1800i Automated Hematology Analyzer with electrical impedance method was purchased from Sysmex Co.

Laboratory examination. Venous blood samples $(5 \mathrm{ml})$ were collected from all subjects and centrifuged at 2,000 $\mathrm{x}$ g for $10 \mathrm{~min}$ at room temperature. Following centrifugation, the serum was collected and used for the detection of IL-6, CK, $\mathrm{CK}-\mathrm{Mb}$, CRP, ALP and LDH, while whole-blood samples were used for blood analyses and detection of LYM, LYM\%, NEU and NEU\%. All specimens were detected within $2 \mathrm{~h}$ of acquisition.

Statistical analysis. All statistical analyses were performed using SPSS 23.0 software (IBM Corp.). Continuous variables are expressed as the mean \pm standard deviation. Comparisons between two groups were performed using unpaired Student's t-tests, while those among multiple groups were determined with one-way ANOVA. In addition, multiple comparisons between two groups were carried out using Tukey's post hoc test. Count data are expressed as n (\%) and comparisons of count data between two groups were performed with a $\chi^{2}$ test. Non-normally distributed data are presented as the median and interquartile range and the Wilcoxon rank-sum test was utilized for comparisons between groups. Furthermore, receiver operating characteristic curves (ROC) were constructed and the area under the curve (AUC) and the best cut-off values were calculated using GraphPad Prism 6.0 software (GraphPad Software, Inc.). Pearson's correlation analysis was used to analyze the correlation between variables, with $|r|>0.3$ indicating a significant correlation. Finally, $\mathrm{P}<0.05$ was considered to indicate a statistically significant difference.
Table I. Baseline characteristics of patients and healthy individuals ().

\begin{tabular}{lcc}
\hline Variable & $\begin{array}{c}\text { Patients with } \\
\text { COVID-19 } \\
(\mathrm{n}=84)\end{array}$ & $\begin{array}{c}\text { Healthy } \\
\text { controls } \\
(\mathrm{n}=30)\end{array}$ \\
\hline $\begin{array}{l}\text { Age (median, years) } \\
\text { Sex, } \mathrm{n}(\%)\end{array}$ & $51(21-91)$ & $51(22-80)$ \\
$\begin{array}{l}\text { Males } \\
\text { Females }\end{array}$ & $37(44)$ & $14(47)$ \\
\hline
\end{tabular}

COVID-19, coronavirus disease 2019.

The cut-off value for common COVID-19 was 0.42 , according to the binary regression equation logistic $(\mathrm{P})=-5.92 \times \mathrm{LYM}+$ $0.004 \times \mathrm{CK}+10.46$; and the cut-off value for the severe type was 0.50 , according to $\mathrm{P}=-145.78 \times \mathrm{LYM}+2.16 \times \mathrm{CK}+109.77$.

\section{Results}

Clinical features of patients with COVID-19. Patients with COVID-19 were admitted to Tianjin Haihe Hospital (Tianjin, China) and underwent routine hematological and biochemical tests. In addition, the serum levels of IL- 6 were determined. The values of the aforementioned parameters in patients with common and severe COVID-19 are presented in Table II. There were different normal reference values for red blood cells (RBC) and CK between males and females.

Comparison of clinical parameters between different types of COVID-19. The results demonstrated that compared with the healthy group, NEU\% was significantly increased, while WBC, LYM and LYM\% were notably decreased in the patient group. The serum levels of CK-Mb were significantly reduced after treatment. However, increased ALP levels were observed in the cured group compared with the healthy group, indicating COVID-19-induced hysteretic liver injury (Table III). RBC (female), NEU\% and NLR, as well as IL-6 and CRP levels in patients with severe disease were significantly higher compared with those in patients with the common type of COVID-19. In addition, LYM and LYM\% in the severe group were significantly lower than those in the group with the common type. The age and LDH levels in patients with severe COVID-19 were higher compared with those with common COVID-19; however, the differences were not statistically significant $(\mathrm{P}>0.05$; Table IV).

Diagnostic efficacy of clinical indicators in patients with COVID-19. Hematological and biochemical parameters, as well as the serum levels of IL-6 and CRP of healthy volunteers and patients with the common and severe type of COVID-19 were subjected to a ROC curve analysis to determine their diagnostic value. The AUC, sensitivity, specificity and cut-off values were calculated. The analysis revealed that the infection monitoring index, LYM and the cardiac marker CK had high diagnostic efficacy, sensitivity and specificity for both common and severe COVID-19. In addition, the 
Table II. Changes in clinical parameters in patients with coronavirus disease 2019.

\begin{tabular}{|c|c|c|c|c|c|c|c|}
\hline \multirow[b]{2}{*}{ Variable } & \multicolumn{3}{|c|}{ Common group $(n=61)$} & \multicolumn{3}{|c|}{ Severe group $(n=23)$} & \multirow{2}{*}{$\begin{array}{c}\text { Normal reference } \\
\text { value range }\end{array}$} \\
\hline & Increased & Normal & Decreased & Increased & Normal & Decreased & \\
\hline \multicolumn{8}{|l|}{$\operatorname{RBC}\left(10^{12} / 1\right)$} \\
\hline Males & $1(4.35)$ & $18(78.26)$ & $4(17.39)$ & $0(0)$ & $11(78.57)$ & $3(21.43)$ & $4.0-5.5$ \\
\hline Females & $0(0)$ & $36(94.74)$ & $2(5.26)$ & $1(11.11)$ & $8(88.89)$ & $0(0)$ & $3.5-5.0$ \\
\hline $\mathrm{WBC}\left(10^{9} / 1\right)$ & $2(3.28)$ & $40(65.57)$ & $19(31.15)$ & $1(4.35)$ & $13(56.52)$ & $9(39.13)$ & $4-10$ \\
\hline $\operatorname{LYM}\left(10^{9} / 1\right)$ & $0(0)$ & 45 (73.77) & $16(26.23)$ & $0(0)$ & $11(47.83)$ & $12(52.17)$ & $0.8-4.0$ \\
\hline LYM\% & $2(3.28)$ & $36(59.02)$ & $23(37.7)$ & $0(0)$ & $9(39.13)$ & $14(60.87)$ & $0.2-0.4$ \\
\hline $\operatorname{NEU}\left(10^{9} / 1\right)$ & $4(6.56)$ & 48 (78.69) & $9(14.75)$ & $1(4.35)$ & $18(78.26)$ & $4(17.39)$ & $2-7.5$ \\
\hline NEU\% & $12(19.67)$ & $45(73.77)$ & $4(6.56)$ & $10(43.48)$ & $13(56.52)$ & $0(0)$ & $0.5-0.75$ \\
\hline IL-6 (pg/ml) & $22(36.07)$ & $38(62.3)$ & $1(1.64)$ & $19(82.61)$ & $4(17.39)$ & $0(0)$ & $1-10$ \\
\hline CRP (mg/l) & $22(36.07)$ & $32(52.46)$ & $7(11.48)$ & $17(73.91)$ & $6(26.09)$ & $0(0)$ & $1-10$ \\
\hline \multicolumn{8}{|l|}{$\mathrm{CK}(\mathrm{U} / \mathrm{l})$} \\
\hline Males & $3(13.04)$ & $14(60.87)$ & $6(26.09)$ & $4(28.57)$ & $9(64.29)$ & $1(7.14)$ & $55-170$ \\
\hline Females & $5(13.16)$ & $28(73.68)$ & $5(13.16)$ & $3(33.33)$ & $6(66.67)$ & $0(0)$ & $30-135$ \\
\hline CK-Mb (U/1) & $1(1.64)$ & $60(98.36)$ & $0(0)$ & $2(8.7)$ & $21(91.3)$ & $0(0)$ & $0-25$ \\
\hline $\operatorname{ALP}(\mathrm{U} / \mathrm{l})$ & $4(6.56)$ & 55 (90.16) & $2(3.28)$ & $5(21.74)$ & $17(73.91)$ & $1(4.35)$ & $38-126$ \\
\hline LDH (U/l) & $16(26.23)$ & $41(67.21)$ & $4(6.56)$ & $11(47.83)$ & $8(34.78)$ & $4(17.39)$ & $313-618$ \\
\hline
\end{tabular}

Values are expressed as n (\%). RBC, red blood cells; WBC, white blood cells; LYM, absolute number of lymphocytes; LYM\%, percentage of LYM; NEU, absolute number of neutrophils; NEU\%, percentage of NEU; IL-6, interleukin 6; CRP, C-reactive protein; CK-Mb, creatine kinase isoenzyme; ALP, alkaline phosphatase; LDH, lactate dehydrogenase.
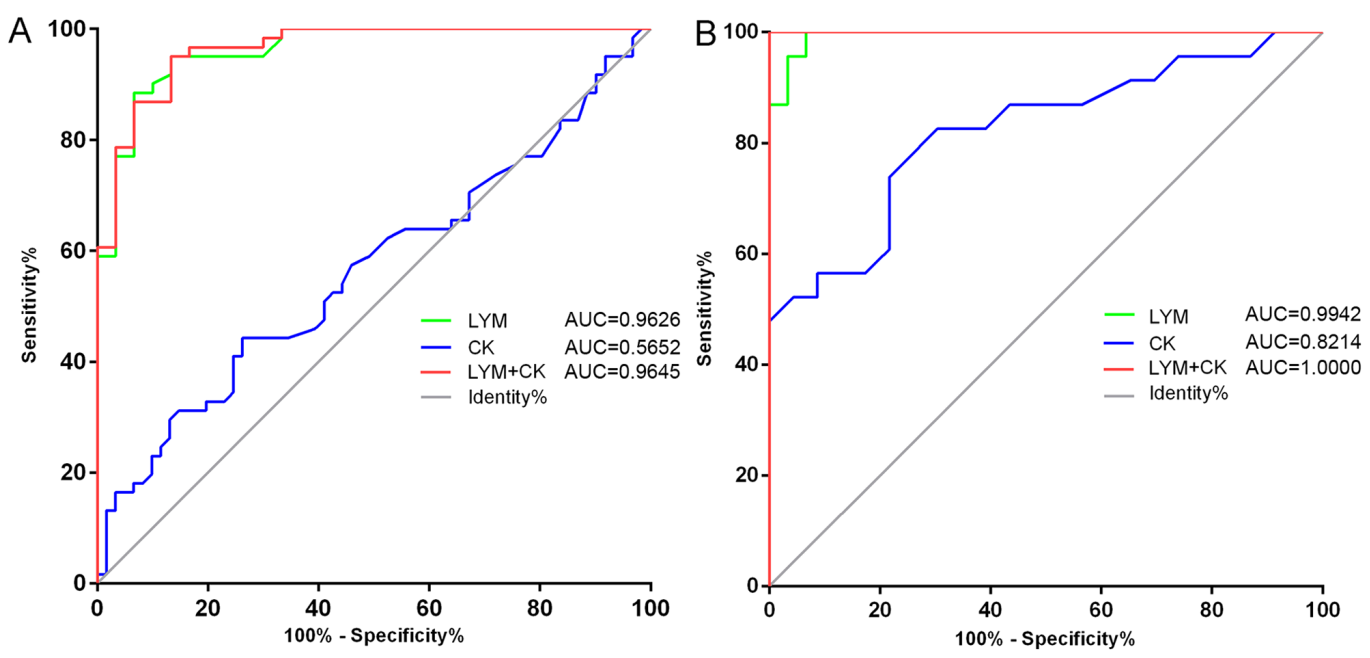

Figure 1. ROC curve analysis for the single and combined detection of LYM and CK in the diagnosis of COVID-19. ROC curves for single and combined detection of LYM and CK in the diagnosis of (A) common COVID-19 and (B) severe COVID-19. ROC, receiver operating characteristic; AUC, area under the curve; LYM, absolute number of lymphocytes; CK, creatine kinase; COVID-19, coronavirus disease 2019.

sensitivity of LYM and CK for severe COVID-19 was higher compared with that for the common type. Of note, the diagnostic efficiency of LYM combined with CK was higher than that of single factors, with improved AUC and sensitivity and specificity, particularly for patients with severe COVID-19, which had a greater AUC (Table V; Fig. 1). The diagnostic efficiency for severe COVID-19 was higher than for common COVID-19.
Correlation between clinical parameters. Correlation analysis between hemocytes, myocardial enzymes and inflammatory factors in patients with COVID-19 indicated that both lymphocytes and neutrophils (particularly LYM and LYM\%) were significantly correlated with IL-6 and CRP, suggesting that lymphocytes and neutrophils were related to the degree of infection in patients with COVID-19. However, CK-Mb and ALP were not significantly correlated with IL-6 and 
Table III. Comparison of clinical parameters in patients with coronavirus disease 2019.

\begin{tabular}{|c|c|c|c|c|}
\hline Variable & $\begin{array}{l}\text { Healthy group } \\
\qquad(n=30)\end{array}$ & $\begin{array}{l}\text { Disease group } \\
\quad(n=84)\end{array}$ & $\begin{array}{l}\text { Cured group } \\
\quad(n=84)\end{array}$ & F-value \\
\hline \multicolumn{5}{|l|}{$\operatorname{RBC}\left(10^{12} / 1\right)$} \\
\hline Males & $4.88(4.57,4.98)$ & $4.46(4.05,4.71)$ & $4.08(3.78,4.54)$ & 13.34 \\
\hline Females & $4.43(4.24,4.57)$ & $3.96(3.89,4.24)$ & $3.86(3.43,4.02)$ & 18.01 \\
\hline $\mathrm{WBC}\left(10^{9} / 1\right)$ & $6(5.46,6.93)$ & $4.61(3.67,5.74)^{\mathrm{a}}$ & $5.6(4.90,6.55)^{\mathrm{b}}$ & 9.86 \\
\hline $\operatorname{LYM}\left(10^{9} / 1\right)$ & $2.15(1.93,2.41)$ & $0.99(0.67,1.28)^{\mathrm{a}}$ & $1.46(1.18,1.76)^{\mathrm{a}, \mathrm{b}}$ & 63.11 \\
\hline LYM\% & $0.36(0.32,0.40)$ & $0.22(0.16,0.29)^{\mathrm{a}}$ & $0.27(0.20,0.31)^{\mathrm{a}, \mathrm{b}}$ & 32.25 \\
\hline NEU $\left(10^{9} / 1\right)$ & $3.39(2.74,4.01)$ & $2.89(2.32,4.00)$ & $3.4(3.00,4.09)$ & 0.92 \\
\hline NEU\% & $0.56(0.48,0.58)$ & $0.67(0.61,0.75)^{\mathrm{a}}$ & $0.62(0.56,0.69)^{\mathrm{a}, \mathrm{b}}$ & 19.54 \\
\hline NLR & $1.61(1.21,1.78)$ & $3.01(2.10,4.88)$ & $2.26(1.79,3.42)$ & 1.181 \\
\hline IL-6 (pg/ml) & $2.00(1.50,2.63)$ & $9.47(2.81,29.8)^{\mathrm{a}}$ & $3.9(1.50,9.60)^{\mathrm{a}, \mathrm{b}}$ & 18.30 \\
\hline $\mathrm{CRP}(\mathrm{mg} / \mathrm{l})$ & $1.07(0.52,1.65)$ & $9.78(3.45,36.92)^{\mathrm{a}}$ & $2.72(1.18,5.59)^{\mathrm{a}, \mathrm{b}}$ & 15.58 \\
\hline \multicolumn{5}{|l|}{ CK (U/l) } \\
\hline Males & $51(43,61)$ & $84(64,121)^{\mathrm{a}}$ & $60(44,78)$ & 3.63 \\
\hline Females & $43(34,50)$ & $50(36.5,75)^{\mathrm{a}}$ & $45(34,57)$ & 2.28 \\
\hline CK-Mb (U/1) & $6(6,8)$ & $7.5(5,11)^{\mathrm{a}}$ & $6(4,9)^{\mathrm{b}}$ & 2.60 \\
\hline $\operatorname{ALP}(\mathrm{U} / \mathrm{l})$ & $55(47,61)$ & $59(51,75)^{\mathrm{a}}$ & $77(61,92)^{\mathrm{a}}$ & 4.74 \\
\hline LDH (U/l) & $485.0(453.1,542.5)$ & $505.5(416.5,638.5)$ & $484.5(411.8,538.3)$ & 1.02 \\
\hline
\end{tabular}

${ }^{\mathrm{a}} \mathrm{P}<0.05$, compared with the healthy group; ${ }^{\mathrm{b}}<0.05$, compared with the disease group. Values are expressed as the median (interquartile range). The disease group refers to patients at first admission to the hospital. RBC, red blood cells; WBC, white blood cells; NLR, neutrophil-to-lymphocyte ratio; LYM, absolute number of lymphocytes; LYM\%, percentage of LYM; NEU, absolute number of neutrophils; NEU\%, percentage of NEU; IL-6, interleukin 6; CRP, C-reactive protein; CK-Mb, creatine kinase isoenzyme; ALP, alkaline phosphatase; LDH, lactate dehydrogenase.

Table IV. Comparison of clinical parameters in patients with different types of coronavirus disease $2019(\mathrm{n}=84)$.

\begin{tabular}{|c|c|c|c|}
\hline Variable & Common group & Severe group & P-value ${ }^{a}$ \\
\hline Age (years) & $48(36,63)$ & $56(44,64)$ & 0.3442 \\
\hline \multicolumn{4}{|l|}{$\operatorname{RBC}\left(10^{12} / 1\right)$} \\
\hline Males & $4.1(3.94,4.54)$ & $4.27(4.00,4.45)$ & 0.2875 \\
\hline Females & $4.03(3.88,4.47)$ & $4.43(4.27,4.70)$ & 0.0326 \\
\hline WBC $\left(10^{9} / 1\right)$ & $4.62(3.84,5.78)$ & $4.29(3.47,5.36)$ & 0.2354 \\
\hline LYM $\left(10^{9} / 1\right)$ & $1.07(0.79,1.41)$ & $0.77(0.56,1.10)$ & 0.0024 \\
\hline LYM\% & $0.24(0.18,0.29)$ & $0.18(0.13,0.24)$ & 0.0440 \\
\hline NEU $\left(10^{9} / 1\right)$ & $2.89(2.32,4.08)$ & $2.92(2.35,3.95)$ & 0.8130 \\
\hline NEU\% & $0.64(0.59,0.74)$ & $0.74(0.66,0.77)$ & 0.0144 \\
\hline NLR & $2.69(2.07,4.08)$ & $4.26(2.81,5.89)$ & 0.0280 \\
\hline IL-6 (pg/ml) & $7.3(2.00,18.9)$ & $30.8(14.75,51.90)$ & 0.0002 \\
\hline CRP (mg/l) & $7.21(2.84,21.1)$ & $40.2(13.11,54.90)$ & $<0.0001$ \\
\hline \multicolumn{4}{|l|}{ CK (U/l) } \\
\hline Males & $75(54.5,130)$ & $84.5(64.25,155)$ & 0.0957 \\
\hline Females & $50(32,71)$ & $99(60,179)$ & 0.0847 \\
\hline $\mathrm{CK}-\mathrm{Mb}(\mathrm{U} / \mathrm{l})$ & $8(6,11)$ & $6(4,10)$ & 0.2126 \\
\hline $\operatorname{ALP}(\mathrm{U} / \mathrm{l})$ & $59(51,73)$ & $57(51.5,98)$ & 0.6025 \\
\hline LDH (U/l) & $498(415,619)$ & $618(433,772)$ & 0.1635 \\
\hline
\end{tabular}

${ }^{\mathrm{a}} \mathrm{P}<0.05$, severe vs. common group. Values are expressed as the median (interquartile range). RBC, red blood cells; WBC, white blood cells; LYM, absolute number of lymphocytes; LYM\%, percentage of LYM; NEU, absolute number of neutrophils; NEU\%, percentage of NEU; NLR, neutrophilto-lymphocyte ratio; IL-6, interleukin 6; CRP, C-reactive protein; CK, creatine kinase; ALP, alkaline phosphatase; LDH, lactate dehydrogenase. 
Table V. Diagnostic efficacy of different clinical indicators in patients with coronavirus disease 2019.

\begin{tabular}{|c|c|c|c|c|}
\hline $\begin{array}{l}\text { Variable/ } \\
\text { symptom type }\end{array}$ & AUC & $\begin{array}{c}\text { Sensitivity } \\
(\%)\end{array}$ & $\begin{array}{c}\text { Specificity } \\
(\%)\end{array}$ & $\begin{array}{c}\text { Cut-off } \\
\text { value }\end{array}$ \\
\hline \multicolumn{5}{|l|}{ Age } \\
\hline Common group & 0.8348 & 26.23 & 96.67 & 36.50 \\
\hline Severe group & 0.5862 & 39.13 & 83.33 & 60.00 \\
\hline \multicolumn{5}{|l|}{$\mathrm{RBC}$} \\
\hline Common group & 0.7708 & 63.93 & 86.67 & 4.26 \\
\hline Severe group & 0.6609 & 69.57 & 66.67 & 4.47 \\
\hline \multicolumn{5}{|l|}{ WBC } \\
\hline Common group & 0.7404 & 65.57 & 83.33 & 5.26 \\
\hline Severe group & 0.8348 & 73.91 & 83.33 & 5.34 \\
\hline \multicolumn{5}{|l|}{ LYM } \\
\hline Common group & 0.9626 & 88.52 & 93.33 & 1.75 \\
\hline Severe group & 0.9942 & 100.00 & 93.33 & 1.69 \\
\hline \multicolumn{5}{|l|}{ LYM\% } \\
\hline Common group & 0.8893 & 77.05 & 90.00 & 0.30 \\
\hline Severe group & 0.9514 & 95.65 & 83.33 & 0.31 \\
\hline \multicolumn{5}{|l|}{ NEU } \\
\hline Common group & 0.5740 & 52.46 & 73.33 & 2.90 \\
\hline Severe group & 0.5870 & 52.17 & 70.00 & 2.97 \\
\hline \multicolumn{5}{|l|}{ NEU\% } \\
\hline Common group & 0.8208 & 70.49 & 86.67 & 0.61 \\
\hline Severe group & 0.9232 & 82.61 & 100.00 & 0.66 \\
\hline \multicolumn{5}{|l|}{ NLR } \\
\hline Common group & 0.8787 & 81.97 & 86.67 & 1.95 \\
\hline Severe group & 0.9391 & 78.26 & 100.00 & 2.63 \\
\hline \multicolumn{5}{|l|}{ IL-6 } \\
\hline Common group & 0.6259 & 62.30 & 62.30 & 4.60 \\
\hline Severe group & 0.8743 & 82.61 & 86.96 & 11.80 \\
\hline \multicolumn{5}{|l|}{ CRP } \\
\hline Common group & 0.7157 & 60.66 & 78.69 & 4.48 \\
\hline Severe group & 0.8544 & 73.91 & 86.96 & 14.54 \\
\hline \multicolumn{5}{|l|}{$\mathrm{CK}$} \\
\hline Common group & 0.5652 & 70.49 & 32.79 & 41.50 \\
\hline Severe group & 0.8214 & 82.61 & 69.57 & 570.00 \\
\hline \multicolumn{5}{|l|}{$\mathrm{CK}-\mathrm{Mb}$} \\
\hline Common group & 0.6360 & 65.57 & 54.10 & 6.50 \\
\hline Severe group & 0.5208 & 47.83 & 56.52 & 6.50 \\
\hline \multicolumn{5}{|l|}{ ALP } \\
\hline Common group & 0.6732 & 65.57 & 67.21 & 65.50 \\
\hline Severe group & 0.6238 & 65.22 & 65.22 & 69.50 \\
\hline \multicolumn{5}{|l|}{$\mathrm{LDH}$} \\
\hline Common group & 0.5649 & 70.49 & 34.43 & 424.50 \\
\hline Severe group & 0.6389 & 65.22 & 43.48 & 475.00 \\
\hline \multicolumn{5}{|l|}{$\mathrm{LYM}+\mathrm{CK}$} \\
\hline Common group & 0.9645 & 95.08 & 86.67 & 0.42 \\
\hline Severe group & 1.0000 & 100.00 & 100.00 & 0.50 \\
\hline
\end{tabular}

RBC, red blood cells; WBC, white blood cells; LYM, absolute number of lymphocytes; LYM\%, percentage of LYM; NEU, absolute number of neutrophils; NEU\%, percentage of NEU; IL-6, interleukin-6; CRP, $\mathrm{C}$-reactive protein; $\mathrm{CK}-\mathrm{Mb}$, creatine kinase isoenzyme; ALP, alkaline phosphatase; LDH, lactate dehydrogenase; NLR, neutrophil-to-lymphocyte ratio; AUC, area under the curve.
CRP, suggesting that myocardial damage may be a secondary symptom after the inflammatory storm. LDH is a myocardial enzyme, which was correlated with CRP, lymphocytes and neutrophils, suggesting that LDH may be an early myocardial damage marker in patients with COVID-19 (Table VI).

\section{Discussion}

COVID-19 is an infectious, progressive disease, which invades multiple organs such as the respiratory, nervous and reproductive systems. Early intervention and treatment may effectively control the progress of the disease (10-13). Clinical experience has indicated that laboratory examination is conducive for the early detection and intervention of COVID-19, thereby effectively reducing the proportion of severe pneumonia, improving the cure rate and reducing mortality. The 'Diagnosis and Treatment Plan for COVID-19' (fifth trial version) (9) has also revealed that timely and early diagnosis and treatment are effective measures for improving the cure rate of patients with COVID-19. Furthermore, routine blood examination, routine biochemical blood tests for liver and kidney function, including the levels of lactic acid, blood glucose, electrolytes and LDH, myocardial injury markers, and CRP and cytokine levels are considered as early clinical warning indicators.

The 'Diagnosis and Treatment Plan for COVID-19 (fifth trial version)' (9) has suggested that the total number of WBCs in peripheral blood is normal or decreased in the early stages of COVID-19, while LYM is decreased. However, in cases of severe COVID-19, the peripheral blood LYM is progressively decreased. In the present study, the results of the routine blood test in 84 patients with COVID-19 were recorded. The results revealed that in patients with common COVID-19, WBC, LYM and LYM\% were significantly decreased, respectively, while the NEU\% was elevated by $19.67 \%$. The rates of $\mathrm{WBC}$, LYM and LYM\% in patients with severe COVID-19 were reduced, while the NEU\% was increased. Compared with those in the healthy control group, LYM and LYM\% were significantly decreased and NEU\% was significantly elevated in the patient group. The levels of all parameters were restored after treatment. In addition, the values of the aforementioned parameters and the NLR in patients with severe COVID-19 were significantly elevated compared with those in healthy individuals. These results were in line with the descriptions proposed by Qin et al (14) and the 'Diagnosis and Treatment Plan for COVID-19 (fifth trial version)' on the role of NLR in the diagnosis of COVID-19, which stated that typically, the 'LYM is normal or decreased and the lymphocyte count is decreased' $(9,15)$.

IL-6 and CRP are important indicators for the auxiliary diagnosis of infectious diseases (16-19). In the present study, the levels of IL- 6 and CRP in the patient group were significantly higher compared with those in the cured group, which was consistent with the descriptions included in the 'Diagnosis and Treatment Plan for COVID-19', stating 'increased CRP and erythroid sedimentation rate in most patients'. The 'inflammatory storm' caused by COVID-19 may lead to myocardial injury and abnormal liver function. It is also stated in the 'Diagnosis and Treatment Plan for COVID-19' that there may be an 'increase of lactate dehydrogenase, muscle enzyme and myoglobin in some patients' and 'increase of liver enzymes in some patients'. 
Table VI. Correlation analysis of the clinical parameters in patients with coronavirus disease 2019.

\begin{tabular}{lcccccccccccc}
\hline Variable & RBC & LYM & LYM\% & NEU & NEU\% & IL-6 & CRP & CK & CK-Mb & ALP & LDH & NLR \\
\hline RBC & - & 0.045 & 0.106 & -0.097 & -0.073 & $-0.214^{\mathrm{a}}$ & -0.113 & $0.182^{\mathrm{a}}$ & $0.220^{\mathrm{a}}$ & 0.006 & -0.054 & $-0.180^{\mathrm{a}}$ \\
LYM & 0.045 & - & $0.691^{\mathrm{a}}$ & 0.046 & $-0.631^{\mathrm{a}}$ & $-0.229^{\mathrm{a}}$ & $-0.416^{\mathrm{a}}$ & -0.142 & -0.050 & -0.113 & $-0.260^{\mathrm{a}}$ & $-0.313^{\mathrm{a}}$ \\
LYM\% & 0.106 & $0.691^{\mathrm{a}}$ & - & $-0.576^{\mathrm{a}}$ & $-0.948^{\mathrm{a}}$ & $-0.311^{\mathrm{a}}$ & $-0.479^{\mathrm{a}}$ & $-0.247^{\mathrm{a}}$ & -0.107 & $-0.187^{\mathrm{a}}$ & $-0.356^{\mathrm{a}}$ & $-0.435^{\mathrm{a}}$ \\
NEU & -0.097 & 0.046 & $-0.576^{\mathrm{a}}$ & - & $0.633^{\mathrm{a}}$ & $0.166^{\mathrm{a}}$ & $0.253^{\mathrm{a}}$ & $0.284^{\mathrm{a}}$ & $0.213^{\mathrm{a}}$ & 0.043 & $0.306^{\mathrm{a}}$ & $0.448^{\mathrm{a}}$ \\
NEU\% & -0.073 & $-0.631^{\mathrm{a}}$ & $-0.948^{\mathrm{a}}$ & $0.633^{\mathrm{a}}$ & - & $0.305^{\mathrm{a}}$ & $0.469^{\mathrm{a}}$ & $0.256^{\mathrm{a}}$ & 0.090 & $0.175^{\mathrm{a}}$ & $0.400^{\mathrm{a}}$ & $0.469^{\mathrm{a}}$ \\
IL-6 & $-0.214^{\mathrm{a}}$ & $-0.229^{\mathrm{a}}$ & $-0.311^{\mathrm{a}}$ & $0.166^{\mathrm{a}}$ & $0.305^{\mathrm{a}}$ & - & $0.549^{\mathrm{a}}$ & 0.132 & 0.020 & 0.073 & $0.281^{\mathrm{a}}$ & $0.220^{\mathrm{a}}$ \\
CRP & -0.113 & $-0.416^{\mathrm{a}}$ & $-0.479^{\mathrm{a}}$ & $0.253^{\mathrm{a}}$ & $0.469^{\mathrm{a}}$ & $0.549^{\mathrm{a}}$ & - & $0.266^{\mathrm{a}}$ & 0.074 & 0.099 & $0.492^{\mathrm{a}}$ & $0.469^{\mathrm{a}}$ \\
CK & $0.182^{\mathrm{a}}$ & -0.142 & $-0.247^{\mathrm{a}}$ & $0.284^{\mathrm{a}}$ & $0.256^{\mathrm{a}}$ & 0.132 & $0.266^{\mathrm{a}}$ & - & $0.769^{\mathrm{a}}$ & 0.080 & $0.256^{\mathrm{a}}$ & $0.268^{\mathrm{a}}$ \\
CK-Mb & $0.220^{\mathrm{a}}$ & -0.050 & -0.107 & $0.213^{\mathrm{a}}$ & 0.090 & 0.020 & 0.074 & $0.769^{\mathrm{a}}$ & - & -0.084 & $0.203^{\mathrm{a}}$ & 0.061 \\
ALP & 0.006 & -0.113 & $-0.187^{\mathrm{a}}$ & 0.042 & $0.175^{\mathrm{a}}$ & 0.073 & 0.099 & 0.080 & -0.084 & - & $-0.268^{\mathrm{a}}$ & -0.006 \\
LDH & -0.054 & $-0.26^{\mathrm{a}}$ & $-0.356^{\mathrm{a}}$ & $0.306^{\mathrm{a}}$ & $0.400^{\mathrm{a}}$ & $0.281^{\mathrm{a}}$ & $0.492^{\mathrm{a}}$ & $0.256^{\mathrm{a}}$ & $0.203^{\mathrm{a}}$ & $-0.268^{\mathrm{a}}$ & - & $0.433^{\mathrm{a}}$ \\
NLR & $-0.180^{\mathrm{a}}$ & $-0.313^{\mathrm{a}}$ & $-0.435^{\mathrm{a}}$ & $0.448^{\mathrm{a}}$ & $0.469^{\mathrm{a}}$ & $0.220^{\mathrm{a}}$ & $0.469^{\mathrm{a}}$ & $0.268^{\mathrm{a}}$ & 0.061 & -0.006 & $0.433^{\mathrm{a}}$ & - \\
\hline
\end{tabular}

${ }^{\mathrm{a}} \mathrm{P}<0.05$. RBC, red blood cells; WBC, white blood cells; LYM, absolute number of lymphocytes; LYM\%, percentage of LYM; NEU, absolute number of neutrophils; NEU\%, percentage of NEU; IL-6, interleukin 6; CRP, C-reactive protein; CK-Mb, creatine kinase isoenzyme; ALP, alkaline phosphatase; LDH, lactate dehydrogenase; NLR, neutrophil-to-lymphocyte ratio.

In the present study, the respective abnormal increase ratio in the common and severe groups were as follows: CK, 13.04 and $28.57 \%$ for males and 13.16 and $33.33 \%$ for females were increased; CK-Mb, 1.64 and 8.7\%; LDH, 26.23 and $47.83 \%$ were increased, and ALP, 6.56 and $21.74 \%$; however, no statistically significant differences were observed. Furthermore, correlation analysis indicated that $\mathrm{LDH}$ was correlated with the infection-related parameters LYM\%, NEU, NEU\% and CRP, suggesting that myocardial injury was closely associated with the progression of inflammation in patients with COVID-19. These results suggested that the aforementioned parameters may be considered as monitoring indicators for the treatment and prognostication of patients infected with SARS-CoV-2.

Yi et al (20) demonstrated that the levels of CK $(93.18 \%$ patients) and CK-Mb (95.45\% patients) were increased in patients with COVID-19. This may be due to the fact that all subjects enrolled suffered from mild COVID-19 and the number of cases included was small. In the present study, 84 patients with common and severe COVID-19 were enrolled and the results suggested that although the levels of $\mathrm{CK}$ in the severe type were higher compared with the common type, the normal CK and CK-Mb range in patients with COVID-19 was only $60.87 \%$ (male) or $73.68 \%$ (female) and $98.36 \%$, respectively. In addition, the rate of the increased CK levels in the severe group was higher than that in the common group, suggesting that CK was closely associated with COVID-19 and may be used as a monitoring indicator for disease course.

The results of the ROC curve analysis revealed that LYM and $\mathrm{CK}$ were superior compared with other parameters in the diagnosis of common and severe COVID-19 and the sensitivity of the combined application of LYM $+\mathrm{CK}$ in the diagnosis of severe and common COVID-19 was $>95$ and $100 \%$, respectively. This result suggested that the combined application of LYM and CK may be used as a reference index for the clinical diagnosis and progress monitoring of COVID-19.

In conclusion, the present study found that the combined application of LYM and CK may be an indicator for the evaluation of COVID-19, as well as the serum levels of IL-6 and CRP in patients with COVID-19.

\section{Acknowledgements}

Not applicable.

\section{Funding}

No funding was received.

\section{Availability of data and materials}

The datasets used and/or analyzed during the current study are available from the corresponding author on reasonable request.

\section{Authors' contributions}

LZ and YD designed the study, checked and confirmed the authenticity of the raw data. ZQ and XW performed the experiments and analyzed the data. All authors read and approved the final manuscript.

\section{Ethics approval and consent to participate}

This study was approved by the Ethics Committee of the Tianjin Haihe Hospital (Tianjin, China). The patients provided their written informed consent for participating in the current study.

\section{Patient consent for publication}

Not applicable.

\section{Competing interests}

The authors declare that they have no competing interests. 


\section{References}

1. Nishiura H, Kobayashi T, Miyama T, Suzuki A, Jung SM, Hayashi K, Kinoshita R, Yang Y, Yuan B, Akhmetzhanov AR, et al: Estimation of the asymptomatic ratio of novel coronavirus infections (COVID-19). Int J Infect Dis 94: 154-155, 2020.

2. Zhang LX, Miao SY, Qin ZH, Wu JP, Chen HY, Sun HB, Xie Y, Du YQ and Shen J: Preliminary analysis of B- and T-cell responses to SARS-CoV-2. Mol Diagn Ther 24: 601-609, 2020

3. Patel NA: Pediatric COVID-19: Systematic review of the literature. Am J Otolaryngol 41: 102573, 2020.

4. Wostyn P: COVID-19 and chronic fatigue syndrome: Is the worst yet to come? Med Hypotheses 146: 110469, 2021.

5. Paliwal VK, Garg RK, Gupta A and Tejan N: Neuromuscular presentations in patients with COVID-19. Neurol Sci 41: 3039-3056, 2020.

6. Krajewska J, Krajewski W, Zub K and Zatoński T: COVID-19 in otolaryngologist practice: A review of current knowledge. Eur Arch Otorhinolaryngol 277: 1885-1897, 2020.

7. MaassenVanDenBrink A, de Vries T, Danser AH: Headache medication and the COVID-19 pandemic. J Headache Pain 1: 38, 2020.

8. Chan KW, Wong VT and Tang SCW: COVID-19: An update on the epidemiological, clinical, preventive and therapeutic evidence and guidelines of integrative Chinese-Western Medicine for the management of 2019 novel coronavirus disease. Am J Chin Med 48: 737-762, 2020.

9. National Health Commission of the People's Republic of China Diagnosis and treatment plan for COVID-19 (trial version 5 revised version)[EB/OL].(2020-02-08)[2020-02-15].http://www.nhc.gov.cn/ xcs/zhengcwj/202002/d4b895337e19445f8d728fcafle3e13a.shtml. (In Chinese)

10. Chan JF, Zhang AJ, Yuan S, Poon VK, Chan CC, Lee AC, Chan WM, Fan Z, Tsoi HW, Wen L, et al: Simulation of the clinical and pathological manifestations of Coronavirus Disease 2019 (COVID-19) in golden Syrian hamster model: Implications for disease pathogenesis and transmissibility. Clin Infect Dis 71: 2428-2446, 2020.
11. Dong L, Tian J, He S, Zhu C, Wang J, Liu C and Yang J: Possible vertical transmission of SARS-CoV-2 from an infected mother to her newborn. JAMA 323: 1846-1848, 2020.

12. Fu J, Huang PP, Zhang S, Yao QD, Han R, Liu HF, Yang Y and Zhang DY: The value of serum amyloid A for predicting the severity and recovery of COVID-19. Exp Ther Med 20: 3571-3577, 2020.

13. Herold T, Jurinovic V, Arnreich C, Lipworth BJ, Hellmuth JC, von Bergwelt-Baildon M, Klein M and Weinberger T: Elevated levels of IL-6 and CRP predict the need for mechanical ventilation in COVID-19. J Allergy Clin Immunol 146: 128-136.e4, 2020.

14. Qin C, Zhou L, Hu Z, Zhang S, Yang S, Tao Y, Xie C, Ma K, Shang K, Wang W and Tian DS: Dysregulation of immune response in patients with COVID-19 in Wuhan, China. Clin Infect Dis 71: 762-768, 2020.

15. Tavakolpour S, Rakhshandehroo T, Wei EX and Rashidian M: Lymphopenia during the COVID-19 infection: What it shows and what can be learned. Immunol Lett 225: 31-32, 2020.

16. Gao Y, Li T, Han M, Li X, Wu D, Xu Y, Zhu Y, Liu Y, Wang X and Wang L: Diagnostic utility of clinical laboratory data determinations for patients with the severe COVID-19. J Med Virol 92: 791-796, 2020.

17. Deng Y, Liu W, Liu K, Fang YY, Shang J, Zhou L, Wang K, Leng F, Wei S, Chen L, et al: Clinical characteristics of fatal and recovered cases of coronavirus disease 2019 in Wuhan, China: A retrospective study. Chin Med J (Engl) 133: 1261-1267, 2020.

18. Lin F, Wu YH, Deng W, Wu PB, Chen JY, Tang SH, Wen JZ, Liu SQ, Lin ZM, Li DF, et al: Clinical analysis and RNA findings in a family with SARS-CoV-2 infection: Case reports. World Acad Sci J 2: 17, 2020.

19. Liu F, Li L, Xu M, Wu J, Luo D, Zhu Y, Li B, Song X and Zhou X: Prognostic value of interleukin-6, C-reactive protein, and procalcitonin in patients with COVID-19. J Clin Virol 127: 104370, 2020.

20. Yi F, Li Z and Li P: Analysis of the clinical value of IL-6, ESR, CRP and routine biochemical tests for the diagnosis of COVID-19. Int J Lab Med 8: 902-915, 2020 (In Chinese). 